\title{
La recuperación mapuche como función clave para una hermenéutico diatópico. Reflexiones a partir de Boaventura De Sousa Santos*
}

\author{
Mapuche recovery as a key function for a diatopic hermeneutic. \\ Reflections from Boaventura De Sousa Santos
}

Torben Albertsen**

\section{RESUMEN}

En Chile, la denominación "intercultural” ya ha llegado a cierta Palabras clave: aceptación institucional. Esta aceptación, no obstante, es poco hermenéuticacrítica y radical. Se requiere, por tanto, repensar su propósito en un proceso que implica volver a sus preguntas epistemológicas y hermenéuticas fundamentales. A partir de la teoría intercultural interculturalmapuchediatópico-crítica de Boaventura De Sousa Santos, este artículo propone tomar el proyecto de la recuperación y revitalización mapuche como una función clave para una hermenéutica diatópica-intercultural. Explicitamos la teoría de Santos de modo general y ejemplificamos el uso diatópico a través de dos ejemplos de recuperación mapuche.

\section{SUMMARY}

In Chile, the term "intercultural" has already gained a certain Keywords: institutional acceptance. This acceptance, however, is uncritical and radical. Therefore, it is necessary to rethink its purpose in a process that involves returning to its fundamental epistemological and hermeneutical questions. Based on the intercultural hermeneuticinterculturalMapuche-diatopiccritical theory of Boaventura De Sousa Santos, this article proposes to take the project of Mapuche recovery and revitalization as a key

\footnotetext{
* El artículo se enmarca en el proyecto Postdoc ANID 20203200009.

** Universidad Técnica Federico Santa María. Master (licenciado) en Historia de las Ideas de la Universidad de Aarhus. Dinamarca. Doctor en Estudios Americanos. Univer-sidad de Santiago de Chile. Chile torbenalbertsen@hotmail.com ORCID ID: https://orcid.org/0000-0002-8578-6377
} 
La recuperación mapuche como función clave para una hermenéutico diatópico | Albertsen

function for a diatopic-intercultural hermeneutics. We explain Santos' theory in general terms and exemplify the diatopic use through two examples of Mapuche recovery. 


\section{Introducción}

En un artículo de Díaz y Samaniego (2015) se propone que la interculturalidad en Chile ha llegado a su "apogeo", y con esta palabra los autores entienden dos aspectos. Primero, que está perdiendo su contextualización y, segundo, que la interculturalidad en Chile se ha popularizado hasta convertirse en una especie de "moda intelectual". Con ambos aspectos el proyecto intercultural está en peligro de perder su proyección más radical y crítica, y, dentro de una sociedad hiper institucionalizada, convertirse en una especie de "certificación vacía". Este artículo es, en parte, un intento por revertir este proceso, con el cual estamos de acuerdo; pero, no vamos a hacer lo que Díaz y Samaniego sugieren como posible solución, es decir, iniciar o sostener una reflexión con corrientes más tradicionales del pensamiento. Aquí proponemos iniciar la reflexión con Boaventura De Sousa Santos, cuya proyección intelectual va hacia la fundamentación epistémica del pensamiento diatópico-intercultural.

En la segunda parte (Una epistemología del Sur) explicitamos su marco general, con el fin de detallar las preguntas que guían el artículo. Hemos separado su marco general en una parte crítica y otra que presenta una alternativa, una estructura reflejada en las últimas dos partes del artículo. Aquí, la tercera parte (el Proceso histórico de la razón indolente) trabaja con la parte crítica, mientras que la cuarta (Hacia una hermenéutica diatópica) con su alternativa.

\section{Una epistemología del Sur}

Boaventura De Sousa Santos, en lo que suele llamar "una epistemología del sur", hace una crítica a la modernidad para distinguir las posibilidades de la emergencia de un nuevo paradigma. Este tiene un doble movimiento; por un lado, se sitúa desde la modernidad y, por otro, intenta ir más allá de ella, sin caer en lo posmoderno ya conocido y que fue central, especialmente en la segunda parte del siglo XX. Santos distingue principalmente dos formas de conocimiento, el conocimiento-regulación y el conocimiento-emancipación (Santos 2003). El punto de partida es la modernidad, ya que en ella había en el pasado un impulso importante de emancipación, en equilibrio con la regulación. El problema contemporáneo es que la emancipación de la modernidad ha ido retrocediendo y reduciéndose, dejando cada vez más terreno 
al tipo de conocimiento que él llama "regulación". Santos define como "conocimiento-regulación" el tipo de conocimiento que tiene como su punto de saber al orden y como su punto de ignorancia el caos; y comprende como "conocimiento-emancipación" al que tiene como su punto de saber a la solidaridad y de ignorancia al colonialismo (Santos 2003). Su tesis central es que el conocimiento-regulación ha ido colonizando al conocimiento-emancipación, transformándolo -y con esto reduciéndolo- a sus parámetros, es decir, dominándolo con el desarrollo de la modernidad tardía.

Cada modo de conocimiento se constituye a partir de tres pilares. Los pilares del conocimiento-regulación se constituyen a partir de tres principios o lógicas: el principio del Estado, el principio del mercado y el principio de la comunidad. Por otro lado, los pilares del conocimiento-emancipación se constituyen a partir de tres lógicas de racionalidad: la racionalidad estética-expresiva de las artes y la literatura, la cognitivo-instrumental de la ciencia y de la tecnología y la moral-práctica de la ética y del Derecho (Santos 2003). La colonización del conocimiento-emancipación a partir del conocimientoregulación fue un proceso que, por un lado, favorecía al principio del Estado - y especialmente al principio del mercado- en detrimento del principio de la comunidad; por el otro, se instaló la racionalidad cognitivo-instrumental como la lógica fundamental desde la cual se colonizó a las otras lógicas, y ello se hizo desde los principios del Estado y el mercado. La racionalidad cognitivo-instrumental se convirtió en fuerza productiva y los criterios de eficiencia y eficacia se convirtieron en hegemónicas, siguiendo la idea de lo bueno del orden contra lo malo del caos. Este es el núcleo-histórico de su crítica y ha tenido diferentes efectos en las otras racionalidades. En el caso de la racionalidad moral-práctica, el Derecho es un ejemplo específicamente relevante para Santos, porque muestra cómo el Derecho y la práctica jurídica están completamente sujetos o colonizados por la racionalidad cognitivo-instrumental. El caso de la racionalidad estético-expresiva es un poco diferente porque - Santos argumenta- todavía retiene cierta autonomía. El problema es que dicha autonomía, que se ha logrado a través de la institucionalización del arte como autónomo, impide al mismo tiempo al arte ser un punto de crítica del mundo no artístico (Santos 2003 129) que, a la vez que lo protege, lo excluye de opinar sobre la racionalidad cognitiva-instrumental y 
los ámbitos de la vida fuera del arte. Un caso similar son los estudios humanísticos que, al resistir la separación objeto/sujeto y preferir la comprensión a la manipulación del mundo, también retienen cierta autonomía respecto de la racionalidad cognitiva-instrumental (Santos 2003 104).

Con la transformación de la racionalidad cognitivo-instrumental en fuerza productiva, cuyo propósito ya no es el de la emancipación sino la regulación principalmente en favor del mercado y el Estado, la racionalidad científica se ha convertido en una razón indolente, cuyo principal propósito es colonizar y apropiarse del mundo en todas sus formas: lo humano, lo social y la naturaleza, o sea, cada ámbito hecho desde diferentes énfasis disciplinarios. El impulso de la emancipación, con su encanto, humildad y curiosidad por la realidad, ha dejado de ser importante en la versión indolente y se ha transformado en un conocimiento-regulación, desencantado, absoluto y no curioso acerca de nuevas experiencias o alternativas. Este impulso lo llama también "injusticia cognitiva", en la medida en que solamente justifica un tipo de conocimiento como válido por la exclusividad de rigor que tiene. ¿No será que el apogeo intercultural es el resultado de un proceso similar - por ejemplo, transformando el conocimiento mapuche en mercancías (turismo) y la educación intercultural en un "productor de certificados" - a favor del poder institucional del mercado y el Estado?

La razón indolente opera en la medida que construye lo que Santos denomina "límites abismales" (2010A 2010B). Aquí se puede entender el conocimiento-regulación como un conocimiento cuya regulación requiere distinguir y limitar entre lo que se considera conocimiento verdadero -o "conocimientos del orden" - frente a conocimientos falsos, o "del caos". Mientras que la tensión entre regulación y emancipación es parte de la experiencia desde la modernidad misma, la experiencia desde el otro lado del límite abismal es la experiencia colonial. En el lado colonial, la tensión no es entre regulación y emancipación, sino entre apropiación y violencia (Santos 2010B 30). En una de sus definiciones más concentradas de "colonialismo", explica que es la incapacidad de establecer una relación con el otro, es decir, la incapacidad de construir una relación de solidaridad y reciprocidad con este otro (Santos 2003 92), o lo que se coloca al otro lado del límite abismal. Mientras que dentro de la modernidad puede haber límites propios o 
internos, los límites que se definen como abismales son caracterizados por una relación con algo exterior a sí mismo, un conocimiento que ha sido silenciado, ignorado e invisibilizado. A pesar de referirse a un mundo exterior, los límites abismales son de por sí parte del fundamento de la modernidad y su pensamiento. La ciencia moderna tiene una función clave en esta limitación, como explica Santos: "en el campo del conocimiento, el pensamiento abismal consiste en conceder a la ciencia moderna el monopolio de la distinción universal entre lo verdadero y lo falso", (2010B 31). La ciencia moderna, por lo tanto, es clave para entender el límite abismal y sus pautas de configuración epistemológica.

La alternativa de Santos reestablece conexiones entre los conocimientos que han sido separados por el límite abismal - un pensamiento posabismal-. De modo general, esta tarea la define como una ecología de saberes, y la llama "ecología" porque se refiere al reconocimiento de la pluralidad de conocimientos heterogéneos, uno de los cuales es la ciencia moderna (Santos 2010B 49). En esta idea todos los conocimientos son limitados y locales, cada uno con sus límites, parcialidades e ignorancias, tal como con sus conocimientos y formas de emancipación. La ecología de saberes presupone por lo tanto la diversidad y pluralidad epistemológica del mundo. El privilegio y monopolio del conocimiento de tipo teórico/general ha construido una relación de reducción y apropiación con otras formas de conocimiento. En vez de esta unificación indolente, abismal y regulativa, propone un pensamiento cuyo objetivo es construir una pluralización y multiplicación de las formas del conocimiento. En versión corta, en vez de unificar lo plural propone pluralizar lo unificado. Para lograr eso hay que aceptar que la comprensión del mundo occidental, moderno y científico es también parcial y local. Al reconocer esta parcialidad se entiende, al mismo tiempo, que el mundo es mucho más que el mundo de esta localidad. Esta inmensa diversidad es lo que ha estado ausente con la razón indolente y su límite abismal, y hay que abrir camino para que ella florezca. Para Santos, todas las culturas son incompletas de por sí, a esto lo llama el "universalismo negativo". Este corresponde a cómo redefinir el conocimiento para la solidaridad. Santos redefine el conocimiento básicamente como reconocimiento (Santos 2003 31), es decir, conocer es reconocer y esto apunta a una elevación del otro de la condición del objeto a la de 
sujeto. Es decir, la condicionalidad social del conocimiento-emancipación se rige por un compromiso ético-solidario, que exige un reconocimiento del otro como un productor propio de conocimiento alternativo. Es necesario reubicar y con esto hacer emerger a los conocimientos ubicados al otro lado abismal. Eso corresponde a lo que llama una "reafirmación del caos como forma de saber y no como ignorancia” (Santos 2003 87).

Santos trabaja generalmente con diferentes propuestas: una sociología de las ausencias, una sociología de las emergencias y el trabajo de traducción. Las primeras dos se tratan de detectar, reubicar y hacer emerger los conocimientos ausentes, mientras que el trabajo de traducción, que propone como parte de la ecología de saberes (Santos 2010A 69), se ubica como una forma de hacer un diálogo y construir algo común entre lo que se sitúa en los dos lados del límite abismal. Como un procedimiento - lo describe como una búsqueda de proporción y correspondencia-, lo que permite aproximaciones a lo extraño a partir de lo familiar (Santos 2010A 69). El trabajo de traducción es pensado como un reemplazo a la teoría general e intenta crear inteligibilidad recíproca en su tarea de identificar homologías entre las diferentes comprensiones de mundos y saberes, es decir, en la pluralización de conocimientos. En vez de reducir la diversidad con la teoría general, la traducción permite mantener y ampliar la diversidad en la comprensión mutua entre saberes; un procedimiento que permite crear inteligibilidad recíproca. Esta tarea es lo que Santos asume como una hermenéutica diatópica. La idea de una hermenéutica diatópica viene originalmente de Raimon Panikkar (1979), quien distingue una hermenéutica diatópica de otra dialéctica. La diferencia consiste en que la dialéctica es histórica y se refiere a solo un lugar (topos), y es tradición de comprensión y autocomprensión; mientras que la diatópica cruza diferentes lugares, tradiciones y culturas.

Como el pensamiento indolente y abismal consiste en conceder a la ciencia moderna el monopolio de la distinción entre lo verdadero y lo falso, procedemos a trabajar en la primera parte con la conceptualización histórica de la ciencia moderna en Santos. El propósito aquí es analizar y ejemplificar algunas de las formas en que la ciencia moderna ha construido su límites internos y externos o abismales, límites fundamentales para su forma de pensarse como universal. 
Concluimos esta parte mostrando la argumentación histórica que Santos usa para intentar desarmar este pensamiento universal, lo que fundamenta de modo histórico su idea crítica del universalismo negativo.

En la segunda parte proponemos conceptualizar la recuperación mapuche como clave para desarrollar una hermenéutica diatópica de índole crítica para superar el apogeo. Para ello usamos dos ejemplos concretos: la recuperación de un mapa mapuche, originalmente publicado en la revista Azkintuwe, y una recuperación del we xipan$t u$, el año nuevo mapuche. Proponemos este intento como un trabajo de traducción dentro de la idea de una ecología de saberes de Santos.

\section{El proceso histórico de la razón indolente}

En esta sección tratamos de presentar la crítica histórica de Santos. Nos parece que esta crítica no es exclusiva de Santos, por lo que intentamos mostrar la suya se cruza con la de autores que han contemplado una perspectiva histórica similar.

El modelo de racionalidad que preside la ciencia moderna se constituyó a partir de la revolución científica del siglo XVI y fue desarrollado en los siglos siguientes básicamente en el dominio de las ciencias naturales. Aunque con algunos presagios en el siglo XVIII, es sólo en el siglo XIX cuando este modelo de racionalidad se extiende a las emergentes ciencias sociales. A partir de entonces puede hablarse de un modelo global de racionalidad científica que admite variedad interna pero que se distingue y defiende, por vía de fronteras palpables y ostensiblemente vigiladas, de dos formas de conocimiento no científico (y, por lo tanto, irracional) potencialmente perturbadoras e intrusas: el sentido común y las llamadas humanidades o estudios humanísticos (en los que se incluirán, entre otros, los estudios históricos, filológicos, jurídicos, literarios, filosóficos y teológicos) (Santos 2009 21).

Santos se refiere, por lo tanto, a los límites establecidos por la ciencia moderna misma en una primera instancia histórica en el siglo XVI. Este proceso es todavía limitado hasta que se establece como dominante fuera de la ciencia natural característica del siglo XIX y que globaliza la racionalidad cognitiva-instrumental. En sus fundamentos, 
Santos (2009 24) apunta especialmente a la importancia de la matemática para la ciencia, no solo como el instrumento privilegiado del análisis, sino que además como el ámbito que guía la lógica de la investigación. La importancia de la matemática tiene dos consecuencias principales; primero, conocer es cuantificar y lo que no es cuantificable es científicamente irrelevante, y segundo, el método científico se basa en la reducción de la complejidad, conocer significa dividir y clasificar. De acuerdo con la inspiración moderna de este ámbito matemático, se limita y excluye de la racionalidad científica lo que se considera irracional o no científico, y con ello también, y como un límite interno, se excluye a las humanidades.

Bauman (1998) propone que esta predominancia de la matemática se encuentra ya en la perspectiva lineal de Filippo Brunelleschi, que subordina todo espacio social a un espacio puramente geométrico y, por lo tanto, matemático. Esta perspectiva lineal somete la perspectiva subjetiva o personal a un punto específico en el espacio, desde el cual todas las relaciones espaciales se ven exactamente de la misma manera. Con esto reduce las cualidades de la persona que ve - el "quien"al punto en términos cuantificados de la observación, es decir, un espacio y una perspectiva completamente matemáticos. De esta forma, la cuantificación del conocimiento corresponde a la cuantificación del espacio, en el que el punto de la observación no necesita recorrer al sujeto que está mirando y su subjetividad, justamente porque se le considera superado desde una perspectiva universalista. Pero, en tanto se considera a las leyes lineales de la pintura como descubiertas por Brunelleschi, se considera a León Batista Alberti como el fundador de la perspectiva de un solo punto de vista, al inventar un método para diseñar una representación matemáticamente correcta del espacio (Santos 2009 69). En relación con esto, Santos argumenta que, mientras el pintor tiene conciencia de su espectador o su propio punto de vista como una ilusión ideal construida por él, el científico moderno no tiene esta misma conciencia, en cuanto se considera a sí mismo como el espectador ideal.

Al contrario, el científico no fue capaz de hacer tal distinción, dado que tanto el espectador ideal como el espectador significativo se identificaron con sí mismo. Esta circunstancia tornó imposible preguntar por el espectador para quien el científico, como trabajador, 
trabaja. Las consecuencias negativas de esta imposibilidad aumentarán con la conversión de la ciencia en una fuerza productiva... (Santos 2009 71).

En otras palabras, la adaptación para la ciencia moderna de la perspectiva lineal del arte visual para transformar al espacio en matemático fue una adaptación poco crítica de parte de la ciencia moderna. $\mathrm{Y}$ esta misma adaptación se vuelve aún menos crítica cuando la ciencia se convierte en fuerza productiva. Santos relaciona aquello con la distinción que se hace entre lo objetivo, lo neutral y lo absoluto. El científico se vuelve neutral y, por ello, absoluto: no considera ya su propio punto de vista, es decir, su propia perspectiva como algo que deba considerarse en la construcción del conocimiento científico.

Según Santos, solamente a partir del siglo XVIII y la Ilustración este modelo de racionalidad se expande más allá de las ciencias naturales para ser un modelo global, ya solidificado en el siglo XIX, y ello ocurre especialmente con la emergencia de las ciencias sociales en el siglo XIX. De acuerdo con nuestro autor (2009), el surgimiento de las ciencias sociales ocurre en dos vertientes principales, una que intenta seguir estrictamente los principios metódicos y, por ello, la cuantificación en las ciencias naturales, y otra que intenta buscar sus propios métodos, resultando, entre otros, en las metodologías cualitativas. La conclusión de Santos es que, a pesar de que esta última corriente busca constituirse a partir de una crítica de las ciencias naturales, se revela como subsidiaria de ellas. Es lo que se revela por ejemplo en su distinción entre naturaleza y cultura. Pero, a pesar de ser también subsidiaria de las ciencias naturales, la crítica representa además para Santos una primera señal de crisis interna de la ciencia moderna. Pero Santos (2009 31), en primera instancia, ubica la crisis propia del paradigma dominante en la ciencia natural misma, siendo su propio avance científico el que apunta a sus propios límites. Esta crisis parte con Einstein y su teoría de la relatividad, y concluye básicamente en que la matemática es insuficiente o limitada a partir de su propia intervención en la construcción del conocimiento.

Pero Santos no es el único autor que ve en el desarrollo histórico una crisis contemporánea con estas características. En Wallerstein (2004) hay una comprensión histórica similar, a pesar de que su énfasis está más centrado en la taxonomía disciplinar, porque ésta se re- 
laciona con la división del trabajo de la universidad moderna, que es fundamental para él. Wallerstein explica que la división del trabajo en la universidad se basa en una bifurcación importante. Esta bifurcación, aunque inicia su desarrollo mucho antes, finaliza su construcción a los fines del siglo XVIII y en el siglo XIX, es decir, en el mismo periodo al cual hace referencia Santos. Pero Wallerstein va más atrás que Santos en la historia. Esta bifurcación institucional divide la labor de las humanidades y las artes, de la labor de las ciencias naturales. La labor de las humanidades está principalmente en la búsqueda de la variedad o lo específico, lo "ideográfico", mientras que la de las ciencias naturales en la búsqueda de las reglas generales o lo "nomotético".

La bifurcación entre lo general y lo particular se transforma desde una división en áreas de conocimiento - que anteriormente habían hecho los griegos-. En la antigüedad, ellos habían separado el conocimiento en tres áreas principales, lo bello, lo bueno y la verdad (Wallerstein 2004). La bifurcación que se construye con la universidad moderna instala una clara separación entre la verdad, por un lado, y por otro lo bello y lo bueno, de tal forma que las ciencias naturales buscan la verdad, mientras que las humanidades lo bello y lo bueno. Pero mientras los griegos no vieron la división entre las tres áreas del conocimiento como algo tan definitivo, la bifurcación que finaliza en el siglo XIX adquiere una forma más fuerte, porque tiene carácter de oposición (Wallerstein 2004). Desde la ciencia moderna, la búsqueda de la verdad - a través de lo general - se ve en oposición a la búsqueda de lo bello y lo bueno - a través de lo particular-. El punto final del análisis histórico de Wallerstein es que la "batalla" más dura de esta bifurcación no fue peleada ni en las ciencias naturales ni en las humanidades, sino en un nuevo campo intermedio que surgió en este tiempo, cuya área de investigación era "la realidad social". Esta resultó en primera instancia en las disciplinas de la ciencia política, la sociología y la economía, como tres formas que estudiaban la ideología liberal predominante de acuerdo a su separación de la sociedad en tres instancias, el Estado (ciencia política), la sociedad civil (sociología) y el mercado (economía). Este conflicto corresponde al conflicto entre las variantes de las ciencias sociales a las que apunta Santos.

La división laboral de la universidad llevaba a las ciencias, que se preocupaban por estudiar las leyes generales, a considerarse univer- 
sales, ya que estaban separadas y limitadas de (y por tanto liberadas de) las dimensiones de carácter estético y normativo. Es decir, la solidificación e institucionalización, en términos de la división laboral de la universidad en Wallerstein, corresponde a esta bifurcación que separa y pone límites entre lo normativo/estético y la verdad. Esta bifurcación, cuyo desarrollo se inicia mucho antes de los siglos XVIII y XIX y que se corresponde con la crítica histórica de Santos, se puede ver ejemplificada en diferentes procesos históricos. Veamos dos ejemplos:

Un primero puede ser la descripción de Mignolo (1995) del desarrollo de la cartografía occidental basada en la diferenciación entre mapas de siglo XVI y XVII y mapas del siglo XVIII y XIX. Aquí hay una diferenciación bastante marcada, que se visualiza en la desaparición de la narración histórica en los mapas. Lo que desaparece son principalmente las imágenes con contenido narrativo. Las imágenes no solamente de monstruos de mar, sino que, además, las puestas frecuentemente en las esquinas, que ejemplifican la diferenciación entre el nosotros y el otro, o los diferentes pueblos y continentes del mundo -Europa, Asia, África y América-. En los mapas más tempranos, el espacio convergía con la narración, mientras que, a partir del siglo XVIII y completamente visible en el siglo XIX, la narración había desaparecido. Mignolo (1995 300) explica que esta misma distinción fue precipitada por una distinción institucionalizada en el rol de diferentes labores. En España, antes del siglo XVI, los roles oficiales de historiador (narrador) y de geógrafo fueron representados por el mismo oficio, uno que, en el siglo XVI, fue separado en dos. Esta separación institucionalizada de labores precipita la exclusión de la narración del ámbito cartográfico, ya que la cartografía solamente considera su rol nuevo relativo a leyes universales en referencia a las leyes geométricas y puramente espaciales. En este sentido, el desarrollo del mapa en la disciplina de la cartografía se deshace de todas las dimensiones semánticas que no son puramente matemáticas, justamente porque no se consideran parte de la verdad.

En relación con la lengua en general y el diccionario como sistema taxonómico, Wierzbicka (2006) ha investigado cómo la literatura científica, especialmente con el libro de John Lock An Essay on Human Understanding, ha influenciado formas comunes de hablar y de definir las 
palabras en la cultura anglo. Wierzbicka explica cómo este libro de Locke, que fue muy popular en su época, influenció la separación entre, por ejemplo, palabras como "pensar" (think) y "opinión" (opinion) como mero conocimiento inseguro, y la palabra "conocer" (know) como algo enfocado en hechos reales, en referencia a lo empírico real y verdadero. Además, explica cómo se empieza a percibir la emoción y el sentimiento como algo en directa oposición al conocer racional, ya que la emoción toma el sentido de descontrol en oposición a lo racional que se refiere a un conocer frío ( $\mathrm{cool} / \mathrm{cold}$ ). Lo ideal de la adquisición racional del conocimiento es un conocer no comprometido por las emociones, ya que esto lo puede llevar a involucrarse con, por ejemplo, dimensiones normativas. En la cultura anglo del presente esto se traduce en diferentes formas de hablar y lo que Wierzbicka llama "cultural scripts" o modos de usar la lengua en la cultura. En este ejemplo, el conocimiento científico original influenció la lengua cotidiana, que en segunda instancia resultó en una forma de plasmar la misma separación en los diccionarios como taxonomía de la lengua. Ambos ejemplos muestran el impulso científico hacia la bifurcación y cómo se concreta en diferentes sistemas taxonómicos e incluso en el habla cotidiana.

En la mayoría de los límites que aquí hemos expuesto no se puede distinguir claramente si son internos o externos, que corresponde a la diferenciación de Santos entre un límite externo como abismal e interno de la modernidad. De hecho, pareciera más bien que la mayoría de los límites que hemos ejemplificado supone operar en capacidades internas y externas a la vez, dependiendo del contexto en que están aplicadas.

Mientras el paradigma de la modernidad separa las diferentes esferas desde la ciencia misma, es importante para Santos mostrar cómo, al mismo tiempo, y junto con este proceso, sigue en pie la subjetividad del científico en sus construcciones. Para Santos (2003 95), esto permite mostrar cómo la ciencia moderna, además de ser moderna, también es occidental, capitalista y sexista, es decir, cómo su neutralidad aparente también tiene un componente subjetivo. Lo dicho es demostrado por Santos a partir de tres líneas de argumentación relacionadas con la teoría de la evolución de Darwin y la primatología. En primera instancia, argumenta cómo la teoría de Darwin fue inspirada en un contexto local y particular a partir de los análisis de Ruth Hubbard. 
Para Ruth Hubbard, la aceptación tan amplia de la teoría de Darwin halla su base, por un lado, en el hecho de ser una teoría histórica y materialista, congruente con el ambiente intelectual de su tiempo, y por otro lado, en el hecho de ser una teoría intrínsecamente optimista que se adecuaba bien a la ideología meritocrática e individualista envalentonada por los éxitos del mercantilismo inglés, del capitalismo industrial y del imperialismo (...) Efectivamente, la selección natural es una historia de progreso, de expansión, de invasión y de colonización; es en suma, casi una historia natural del capitalismo o una historia del capitalismo natural (Santos 2003 95-6).

Por lo tanto, la teoría del evolucionismo de Darwin, a pesar de ser sobre la naturaleza, tiene un componente intrínseco de la ideología del liberalismo de la época y, por lo tanto, no es solamente moderna o científica sino además capitalista. La segunda argumentación muestra cómo lo moderno además es occidental, y para esto utiliza las comparaciones entre la primatología occidental y la primatología japonesa de Donna Haraway.

Mientras que la primatología occidental considera fundamental la distinción entre hombre y naturaleza, la primatología japonesa se basa en la idea de una continuidad y de una unidad esencial entre seres humanos y animales. A la luz del confucianismo, esa continuidad y unidad no son incompatibles con la idea de jerarquía. Por el contrario, de esta surge una preocupación sobre las cuestiones de estatuto, personalidad, cambio social, estabilidad y liderazgo, de mucha mayor importancia en los estudios japoneses que en los occidentales. Por otro lado, mientras en la primatología occidental la "buena" (noble) naturaleza es la naturaleza salvaje e intocada, en la japonesa, la naturaleza es una obra de arte que puede ser enriquecida por la interacción humana. Véanse, por ejemplo, la domesticación de macacos en cautivo, una práctica que es altamente apreciada en Japón y penalizada en Occidente (Santos 2003 96-7).

De esta forma, los primates - y con ello el estudio de la naturaleza- se vuelven espejo de la cultura y de la sociedad del hombre que lo estudia, en este caso el hombre occidental y el hombre japonés. Los monos y simios tienen en lo occidental una posición privilegiada, porque ocupan una zona de frontera en la distinción entre lo humano y la 
naturaleza. Para el último argumento, que también se basa en el darwinismo, Santos conecta lo moderno con el sexismo y ello se basa en la argumentación de Ruth Bleier.

El reino animal está lleno de machos ávidamente promiscuos en persecución de hembras que se mantiene pasivas, lánguidas y expectativas hasta el momento de elegir un compañero que sea el más fuerte o el más bello. Este sexismo científico se prolonga en la sociobiología, sobre todo en las explicaciones dadas para justificar las asimetrías entre los sexos (Santos 2003 98).

El binomio cultura/naturaleza pertenece a una larga familia de dualismos entre los que podemos distinguir, entre otros, abstracto/concreto, espíritu/cuerpo, sujeto/objeto, ideal/real. Todos estos dualismos son sexistas en la medida en que, en cada uno de ellos, el primer polo es considerado dominante, siendo al mismo tiempo asociado con lo masculino (Santos 2003 97).

En prolongación de esto, Santos argumenta que lo masculino se transforma en un universal, mientras que lo femenino se vuelve un mero punto de vista, cargado de particularismos y vinculaciones naturalistas. Esta argumentación en Santos, acerca del componente subjetivo en la ciencia natural, corresponde al proceso que llama "universalismo negativo", en la medida que intenta mostrar lo particular de las teorías universales. Se entra en una relación contradictoria con los límites en la parte anterior, en la medida en que niegan estos mismos límites y la realidad de concebir la ciencia moderna a través de ellos. Esta contradicción hace énfasis en que el paradigma moderno, y junto con ella su razón indolente y abismal, ya ha estado en crisis desde hace un tiempo.

En Santos, la crisis del paradigma se inicia aproximadamente a principios del siglo XX, mientras que para Wallerstein se inicia en 1968, aunque esta fecha está íntimamente relacionada con lo que pasa en 1945. Esta diferencia se debe a que, mientras Santos está estudiando el paradigma científico y teórico moderno, Wallerstein está abocado al sistema-mundo capitalista, con una perspectiva particular en relación con las taxonomías disciplinarias y, por tanto, con las instituciones científicas. A pesar de esta diferencia, ambos paradigmas se inician en el siglo XVI y ambos entran en crisis en el siglo XX. Además de 
ello, ambas perspectivas sobre la crisis tienen en común la crítica a la taxonomía disciplinar y la búsqueda de una ciencia más holística. Tal ciencia busca, obviamente, cruzar las disciplinas científicas y superar la bifurcación (en Wallerstein) y los límites y dicotomías (en Santos).

En Wallerstein, uno de los nuevos fenómenos que se inician con la revolución de 1968 es, por ejemplo, los estudios interdisciplinarios que empiezan a aparecer en los setentas y ochentas, especialmente en Estados Unidos. Una de las características principales del nuevo paradigma emergente, sobre el cual habla Santos (2009 41), es precisamente que cruza la bifurcación que Wallerstein caracterizó, y que se instala no solamente como un paradigma científico, sino además como un paradigma social. En Santos esto significa que el nuevo paradigma busca reinstalarse o recontextualizarse precisamente en relación con el sentido común y su contexto de producción local, respecto del cual lo moderno había hecho todo para eliminarlo o distanciarse en su producción científica. El nuevo paradigma emergente cruza la bifurcación que es parte fundamental de la taxonomía disciplinar de las ciencias y trata de reconectar, por ejemplo, lo normativo con la epistemología. El cierre disciplinar significa el enclaustramiento de la inteligibilidad de la realidad estudiada, y esto es parcialmente responsable de la reducción de la realidad a una realidad homogénea y con ello hegemónica (Santos 2009 143).

Santos explica que el nuevo conocimiento ya no avanza solo por medio de la especialización sino, además, por medio de la ampliación de su objeto. Aunque la crisis de la razón indolente ya se ha iniciado, todavía tiene mucho poder y aún es la forma más predominante de pensar. Esto se debe a su institucionalización como conocimiento-regulación, principalmente a partir del mercado y el Estado, y no solamente en la universidad, sino que además en las instituciones políticas, económicas, legales, etc., de las sociedades contemporáneas.

Contemplado a partir de esta crisis, su ecología de saberes y su hermenéutica intercultural se estilan hacia los modos alternativos que corresponde con lo holístico y la ampliación del conocimiento para sobrepasar los límites internos y los límites abismales y externos. Con esto llegamos al fin de la primera parte, e intentaremos ahora construir una hermenéutica intercultural basada en su propuesta del trabajo de 
traducción integrada en su ecología de saberes, con el fin de dialogar con la revitalización mapuche.

\section{Hacia una hermenéutica diatópica}

Guillaume Boccara, en su trabajo "The brighter side of the indigenous renaissance. Mapuche symbolic politics and self-representation in today's Wallmapu" (2006), ofrece una representación de un mapa mapuche, publicado originalmente en la revista Azkintuwe. En él se reemplaza el nivel político sin reemplazar el fondo geográfico.

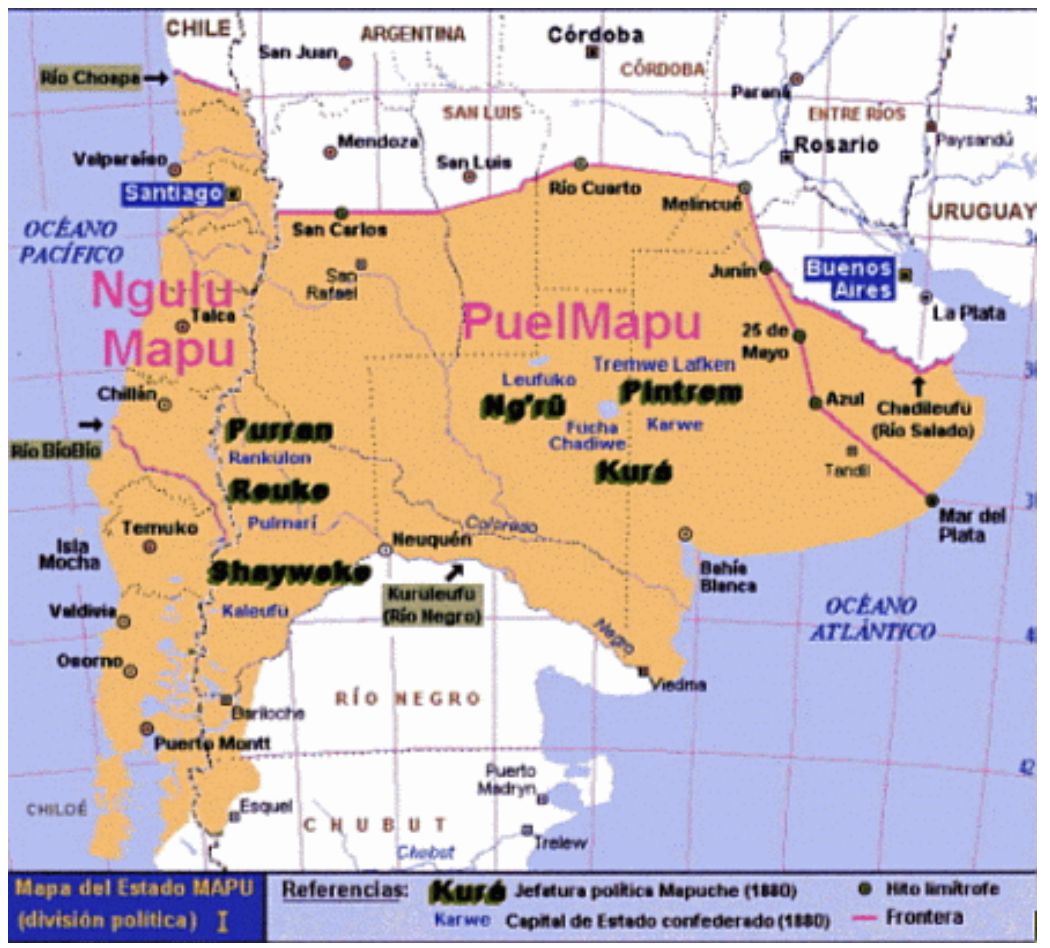

Ilustración no. 1: El MAPU Histórico

Fuente: Boccara, 2006

Aquí la frontera nacional no está presente. En el mapa nacional moderno esta frontera fue naturalizada con la cordillera de los Andes. Con esta alteridad geográfico-política se puede dar cuenta de la correspondencia naturalizada entre narrativa política y matemática geográfica. Es decir, el mapa alternativo mapuche nos presenta una posibilidad 
de ruptura y, con esta ruptura es posible darse cuenta de la narrativa política que acompaña a la geografía, en este caso en relación con la naturalización de las fronteras nacionales. En la imagen aludida, la purificación geográfica que planteó Mignolo ha ocurrido en paralelo con el proceso político y militar de la formación nacional; un proceso que hoy día se ve plasmado comúnmente como colores (las naciones) por encima de la representación geográfica. Hoy en día existen nuevos "monstruos del mar", es decir, una nueva correspondencia entre lo geográfico y lo político. Pues se ha vuelto a reintroducir otra narración en paralelo con la verdad geográfica y, en el caso de la Cordillera de las Andes, reafirmándose a partir de ello. En este caso, la separación política entre Argentina y Chile ha silenciado una historia de unión político-social mapuche. Si consideramos el mapa también como una forma cognitiva de conocimiento, éste brinda un ejemplo de lo que Santos refiere cuando explica que la injusticia social y política no se puede separar de la injusticia cognitiva.

El proceso hermenéutico-epistemológico que se inicia con esta ruptura y ejemplo, me parece corresponde a lo que Santos llama "universalismo negativo", es decir, un proceso de concientización ecológico-diatópico, en el que se puede detectar la parte local (particular) dentro de narrativas que aparecen a primera vista con características globales (generales-universales). Este proceso hermenéutico es crítico frente a la razón indolente y su límite abismal, o, lo que Santos también llama la "lógica metonímica", cuya función principal es reducir lo particular (local) dentro de lo general (global). Esta tarea -la construcción de una hermenéutica diatópica que puede buscar un conocimiento-emancipación - es, por una parte, una ampliación interdisciplinaria y, por otra, una ampliación intercultural, o, dicho de otra forma, se puede tocar ambos límites internos y externos. Con relación al ejemplo del mapa, es interdisciplinario (interno) en cuanto toca la división laboral del conocimiento interno al mundo occidental (geografía y narración) y su forma de reintroducir la narración por encima de la geografía, y es intercultural (externo) en cuanto entra en directo conflicto político-social con la recuperación políticogeográfica mapuche.

Creo que una hermenéutica diatópica podría centrarse en este conflicto y hacerlo clave para su propósito. Es decir, podría orien- 
tarse a construir comparación y traducción a partir de estos tipos de encuentros con recuperaciones indígenas. De este modo, el mapa de Azkintuwe es una recuperación mapuche que puede ocupar un rol emancipativo dentro del propósito de una hermenéutica diatópica. La recuperación presenta una posibilidad epistemológica de detectar los límites naturalizados del conocimiento en la relación entre la geografía y la narrativa, justamente porque en el mundo mapuche esta relación es otra. Frente a una naturalización específica, esta recuperación mapuche se presenta como una especie de "anomalía del paradigma" que, simultáneamente, brinda la posibilidad de emancipación en cuanto poder detectar las estructuras abismales y coloniales y los valores cementados que guían una determinada construcción geográfica-política y colonial. Este es dia-tópico en la medida que va "a través de" (dia) el otro (la recuperación) para dejar que esta relación y comparación nos ayude a detectar aspectos que no solo se vinculan con el mundo mapuche, sino además con nuestras naturalizaciones y límites propios. Es una traducción y comparación en el sentido de Santos, en cuanto se acerca a las "proporciones y correspondencias" entre ambos topos, y, también, en la medida que es una aproximación a lo extraño a partir de algo familiar.

Santos explica que lo que más caracteriza a lo abismal es precisamente la imposibilidad de la co-presencia de los dos lados de la línea (2010B 29-30). Entiendo esta co-presencia, por un lado, en referencia a colocarlos juntos de modo no asimétrico y, por otro, en referencia a no plasmar el mundo indígena hacia el pasado. La recuperación hace referencia precisamente al presente del mundo mapuche en cuando proyección político-social actual. De este modo se intenta evitar la descontextualización del apogeo y localizar el proceso diatópico en una contingencia y topos local y contextualizado. Santos propone que la dificultad principal en hacer una comparación así se relaciona con la asimetría de la relación (2010A 68). La asimetría, en nuestro primer ejemplo, está derivada del propósito mismo de la recuperación en la medida que su proyección político-social busca recuperar precisamente lo que se ha perdido, silenciado y reducido a través de los límites abismales y la razón indolente. Al mismo tiempo, esta relación brinda una posibilidad de ser críticos, una posibilidad que está relacionada con el propósito de la ecología de saberes de operar como contrahegemónica de por sí. Es contrahegemónica en tanto busca reconfigu- 
rar las relaciones jerárquicas entre los saberes, no para desacreditar a la ciencia moderna de por sí, sino para reestablecer su relación como un saber entre otros, y no como el único viable. La emancipación, en el sentido de Santos, vuelve aquí como un reencantamiento hermenéutico con eso que es diferente, pero que puede ser reflejado en algo familiar. Busca situarse con una dimensión autocrítica en la medida en que la diferencia es fuente de autodescubrimiento respecto de los límites propios. No será dentro de este ámbito donde una hermenéutica intercultural podría encontrar un hilo conductor para un proceso de emancipación. Es en este sentido que estamos refiriéndonos a la recuperación mapuche como una función clave para una hermenéutica diatópica.

Una característica de la recuperación del mapa mapuche es que su uso es una crítica política desde el Wallmapu, es decir, su explicitación tiene una función crítica que se refiere a la lucha y la resistencia política del pueblo mapuche. Podríamos, por lo tanto, preguntarnos si otras recuperaciones de carácter explícitamente menos críticos también podrían tener una función o potencial similar para una hermenéutica diatópica. Presentamos ahora un segundo ejemplo de recuperación mapuche que no parece tener una crítica tan explícita.

Este ejemplo es el intento por recuperar un sentido mapuche de la celebración we xipantu, que comúnmente se ha traducido con "año nuevo (mapuche)". El ejemplo está tomado del capítulo "Wiñon antü zugu. Fenómeno natural, de vida y de kimün en el mapunche rakizuam" de Desiderio Catriquir Colipan y Gabriel Llanquinao Llanquinao, en el libro Mapun kimün. Relaciones mapunche entre persona, tiempo y espacio (Becerra Llanquinao 2017). La traducción del we xipantu con "año nuevo (mapuche)" la podemos denominar como un "equívoco", según la propuesta de Viveiros De Castro (2004). Un equívoco no es un error, en la medida que un error presupone un horizonte de comprensión compartido y común. Al contrario, un equívoco se refiere a que no existe un referente común que sería el propósito de la traducción a encontrar. No solo no están hablando la misma lengua o de la misma forma (epistemología), sino además no están hablando de las mismas cosas (ontología). De este modo el equívoco presupone diferencias radicales e incompatibles. Sea o no que se pueda diferenciar a la epistemología de la ontología de este modo, me parece bastante 
obvio, en el caso de la traducción we xipantu-año nuevo, que se está efectivamente hablando de "cosas" diferentes. Vemos las diferencias según los autores.

De modo general, se puede decir que la dirección de la equivocación se debe a diferentes formas de comprender la relación entre lo social y la naturaleza. Por ejemplo, el we xipantu se entiende en acorde con el periodo entre los dos solsticios, es decir, como un periodo prolongado dentro del cual se regenera la vida en la Tierra. La celebración chilena (u occidental en general) del año nuevo ya no tiene nada que ver con el ritmo de la naturaleza y su regeneración prolongada. Es un evento completamente secularizado, incluso sin aspectos tradicionales cristianos, debido probablemente en parte a su origen romano. Además, el año nuevo es celebrado como un evento mucho más específico, la noche que cambia el año en el calendario gregoriano. Dentro del calendario gregoriano, la fecha de la celebración tradicional romana corresponde a la etapa del invierno (enero), no obstante que la celebración del Año Nuevo chileno, y en el Hemisferio Sur, está situado en el verano, es decir, la importancia está puesta en el cambio de fecha del año en el calendario gregoriano más que los cambios de una temporada específica. Incluso si estuviéramos en Dinamarca celebrando el Año Nuevo, es éste también el caso, a pesar de estar situado en invierno. Es decir, la fecha se celebra por el cambio del año en el calendario y no en relación a un cambio de temporada.

La traducción es equívoca entonces por varias razones, una fecha específica en contraste con un periodo prolongado, un sentido secular en contraste con la recuperación de la naturaleza, y en Chile/Argentina es la temporada del verano (enero) frente a la temporada del invierno en el we xipantu (junio). A partir de estos hechos el artículo además saca varios otros asuntos diferentes, por ejemplo, que hay trece meses en el calendario mapuche y no doce, y seis épocas del año y no cuatro. En conclusión, no solamente hay diferencias lingüísticas o epistemológicas (formas de pensar), sino, además, no se está hablando de las mismas "cosas" (¿ontología?). No celebran "lo mismo", no se hace en el mismo "tiempo" y tampoco de "la misma forma". Uno podría seguir esta divergencia preguntando, por ejemplo, por el equívoco de la palabra de "celebración", pero estimamos que es suficiente para nuestra argumentación principal. Si hay que traducir, es mejor pensar la realidad 
de la traducción como un equívoco y presuponer hermenéuticamente que son diferencias radicales.

A veces simplemente no hay buena traducción porque los mundos son radicalmente diferentes. Puede ser parecido al sentido de la frase famosa de que el capitalismo es el peor sistema económico, excepto por todos los demás (que son peores aún). Tal vez la traducción "año nuevo" es la peor traducción, excepto por todas las demás. Pero este hecho, de que es una equivocación no es algo puramente negativo, sino precisamente nos brinda posibilidades que pueden ser positivas, es decir, visto desde una hermenéutica intercultural que considera las diferencias (o equivocaciones) como dispositivos para una nueva objetividad emancipativa-intercultural. La recuperación del we xipantu como celebración está orientada hacia una relación con las temporadas, mientras que el año nuevo está orientado como celebración hacia el cambio del calendario como entidad cuyo significado en esta instancia no tiene ninguna relación con las temporadas de la tierra. Es una celebración hacia la cuantificación en sí, como medida abstracta y lineal del tiempo. Claro que se sigue agregando contenido simbólico a esta cuantificación de por sí, saltando de una silla, comiendo uvas o lentejas, haciendo fuegos artificiales, comprometiéndose para cumplir algo en el nuevo año, etc. La celebración se llena de contenido simbólico-cultural porque la cuantificación científico-lineal está vacía del tipo de contenido que nos llena la vida.

La traducción en sí no parece explicitar un conflicto directamente politizado como el mapa. Aparece más bien como formas culturales de celebrar que podrían coexistir en paralelo sin mucho conflicto entre sí. En este asunto, no obstante, hay que tener cuidado de no caer en una conceptualización multiculturalista limitada y occidental. Un multiculturalismo propone que las culturas son múltiples, pero esta pluralidad solamente se extiende al ámbito cultural mientras que se excluye del ámbito de la naturaleza. En cuanto se excluye la naturaleza, esta conceptualización (multicultural) separa de modo dicotómico el asunto de la cultura como algo epistemológico y múltiple del asunto de la tierra o naturaleza, como algo ontológico, unificado e igual en todas partes (Viveiros De Castro 1998). Es decir, tenemos diferentes culturas, pero una naturaleza única y compartida (genes, biología, evolución, etc.). 
Esta es precisamente una posible equivocación occidental en la traducción, presuponiendo que el mundo mapuche (la noción we xripantu) también construye un límite interno que separa culturas (en plural) de la naturaleza en lo singular y que también comprende la naturaleza como un campo homogéneo y unívoco como la ciencia moderna. Para refutar este asunto se podría mencionar, por ejemplo, los estudios de Bacigalupo (2007) acerca de las prácticas del chamán mapuche (machi), y los estudios de la percepción sobre la enfermedad de Aukanaw (1995). Ambos estudios operan con una percepción sobre la tierra o el mapu (la "naturaleza") que no se puede llamar unívoco o homogéneo, y menos que su verdad transciende y opera independientemente del ámbito cultural. También se puede referir al estudio del tuwün (pertenencia) mapuche de Giminiani (2011). Este rastrea la relevancia cosmológica en los asuntos políticos relacionados con la recuperación de tierras.

Este tipo de cultura, que existe ingenuamente por limitar y excluir a la relación ontológica, es a-politizado y, según lo que aprendimos con la crítica histórica de Santos, a-histórico. Es a-histórico en la medida en que su ideología aspira a una neutralidad científica que pretende no tener relación con su contexto cultural y político, o lo que Santos llamó su "sentido común". En el fondo, y a propósito del apogeo, esta versión folklórica es descontextualizada. El problema es que esta equivocación apunta a diferentes formas de relacionarse con la tierra (ontología-naturaleza), límites que no son compatibles entre sí. Por lo tanto, si aplicamos la idea de "multiculturalismo" frente a recuperaciones como esta, ya estamos reduciendo con la razón indolente el asunto a las dicotomías occidentales y, en consecuencia, no entramos en ninguna relación emancipativa con el mundo mapuche sino más bien mantenemos una relación regulativa, colonial y abismal. A pesar de ser solo una traducción, su equivocación apunta a un fondo y condición que está en directa relación con diversos conflictos políticos contemporáneos respecto de la tierra y su uso. Un fondo comprensivo del mapuche kimün, que hoy en día apenas tenemos una hermenéutica para entender, y menos una política para tratar de resolver.

\section{Conclusiones}

La hermenéutica histórica de Santos sobre la ciencia moderna sugiere una circularidad entre sentido científico y sentido común. Propone 
que necesitamos construir una nueva relación entre ellos, una relación en la que el sentido científico debe aproximarse al sentido común por vía ecológica. Esto requiere también repensar interdisciplinariamente las relaciones entre las diferentes ciencias - naturales, sociales y humanas-, para romper con el conocimiento-regulación y abrirse hacia el conocimiento-emancipación. En clave diatópica, me parece que una hermenéutica intercultural necesita retomar las comparaciones y traducciones hacia las culturas indígenas, con el propósito de reconfigurar las relaciones y asimetrías que surgen a partir de ellos. Tales traducciones apuntan a los límites, internos y externos, que están en juego hermenéuticamente. En nuestros ejemplos apuntamos a algunos conflictos que surgen de modo diatópico a partir de dos recuperaciones mapuche. Primero, a los límites entre la geografía y la narrativa, y su relación abismal-político con la irrupción de la recuperación mapuche; segundo, a los límites entre la naturaleza y la cultura, y lo conflictivo de esta perspectiva desde el mundo mapuche. Este no es una forma de responder y cerrar los asuntos, sino solamente de hacer preguntas constantes con respuestas incompletas, un modo que pretende abrir el pensamiento a reconfigurar las relaciones entre conocimientos. Una hermenéutica diatópica exige que pensemos su función hermenéutica dentro de la sociedad más amplia, lo que nos ha llevado a proponer que una de sus funciones hermenéuticas claves podría darse en relación con la recuperación mapuche, y tal vez, como extensión, con el mundo indígena de modo general. Este tipo de emancipación no es estrictamente histórica, sino intercultural, a pesar de que la historia es importante para ella. En la primera ruptura, el sentido científico se rompió con el sentido común para establecerse como superior a ella. En la segunda, Santos propone que el sentido científico tiene que abrirse e involucrarse de nuevo con el sentido común. Para un propósito diatópico-intercultural, esta segunda ruptura tendría que dedicarse no solo al sentido común de modo general, sino específicamente a la posibilidad de aprender también de los sentidos comunes de otros.

Los límites y las posibilidades de cada saber residen así, en última instancia, en la existencia de otros saberes y, por eso, sólo puede ser explorados y valorizados en la comparación con otros saberes. Cuanto menos un determinado saber conozca los límites de lo que conoce sobre los otros saberes, menos conoce sus propios límites y posibilidades (Santos 2010A 68) 
Una recuperación vista como clave para una hermenéutica diatópica puede operar como punto de crítica del orden y el colonialismo, para hacer emerger nuevas relaciones entre los conocimientos que, a su vez, pueden abrir nuevas relaciones entre los pueblos originales y las sociedades occidentales.

\section{Bibliografía}

Aukanaw. La Ciencia Secreta de los Mapuche. Rosario: Nueva Era, 1995. (http://futatraw.ourproject.org/descargas/libros/aukanawciencia_sec.pdf)

Bacigalupo, M. Shamans of the foye tree, gender, power, and healing among Chilean mapuche, Austin: University of Texas press, 2007.

Bauman, Z. Globalization, The human consequence. New York: Columbia University Press, 1998.

Becerra P, R. y Llanquinao, L, G. Mapun kimün. Relaciones mapuche entre persona, tiempo y espacio, ed. Santiago, Chile: Ocho Libros, 2017.

Boccara, G. "The brighter side of the indigenous renaissance. Mapuche symbolic politics and self-representation in today's Wallmapu (i.e. Chile and beyond)", Nuevos mundos Mundos Nuevos. Debates (2006) (http://nuevomundo.revues.org/2405).

Díaz C, G. y Samaniego, M. "El interminable apogeo de la interculturalidad: algunas reflexiones críticas desde la antropología y la filosofía". Tabula Rasa 22, (2015): 85-105.

Freire, P. Pedagogy of the oppressed, London: Penguin, 1970.

Giminiani, P. D. Ancient Lands, Contemporary Disputes. Land Restoration and Belonging among the Mapuche People of Chile. Phd in Philosophy. London: University College, 2011.

Mignolo, W. The Darker side of the Renaissance, Literacy, Territoriality, and Colonization. Michigan: University of Michigan Press, 1995.

Panikkar, R. Myth, Faith and Hermeneutics. New York: Paulist Press, 1979.

Santos, B, De Sousa. Crítica de la Razón Indolente, Contra el desperdicio de la experiencia, (volumen I) Para un nuevo sentido común: La ciencia, el derecho y la política en la transición paradigmática. (Trad. Flores, H. J. ed. A critica da razao in- 
dolente: contra o desperdicio da experiencia: Para un novo senso común. A ciencia e a política na transicao paradigmática. Volume 1) Bilbao: Desclée de Brouwer, 2003.

Santos, B. De Sousa. Una Epistemología del Sur: La reinvención del conocimiento y la emancipación social. Buenos Aires: Siglo XXI, 2009.

Santos, B. De Sousa. Para descolonizar Occidente. Más allá del pensamiento abismal. Buenos Aires: CLACSO, 2010. (2010A).

Santos, B. De Sousa. Descolonizar el saber, reinventar el poder. Montevideo: Trilce, 2010. (2010B).

Viveiros De Castro, E. "Cosmological Deixis and Amerindian Perspectivism", The Journal of the Royal Anthropological Institute 4/3 (1998): 469-488.

Viveiros De Castro, E. "Perspectival Anthropology and the Method of Controlled Equivocation". Tipití 2/1 (2004): 3-22.

Wallerstein, I. World-System Analysis, an introduction, Durham: Duke University Press, 2004.

Wierzbicka, A. English, Meaning and Culture. New York: Oxford University Press, 2006. 